\title{
A FLAKED FLINT FROM THE RED CRAG.
}

\author{
By Professor W. J. Sollas, D.Sc., LI.D., F.R.S. \\ (Communicated by J. Reid Moir.)
}

\section{[Read at Norwich, January 19th, 1920.]}

The remarkable specimen which forms the subject of this communication was presented to me by Mr. Reid Moir, who had extracted it with his own hands from the base of the Red Crag exposed in Messrs.' Bolton \& Laughlin's brick field, near Ipswich.

It is a fragment of a nodule of chalk flint, irregularly rhombic in outline, with nearly flat base and a rounded upper surface which slopes away on each side from a medium line (the shorter diameter) joining the two obtuse angles of the rhomb.

The upper rounded side formed part of the original surface of the nodule and retains the whitish weathered crust, $8 \mathrm{~mm}$. or more in thickness, which was formed while the nodule lay embedded in the chalk. The exterior of this crust has since been traversed by solutions which have deposited in its pores some silica and ferric hydrate, thus forming a brown superficial layer which is now too hard to be scratched with a knife.

The base (Fig. 64) was probably formed by a natural fracture, which detached the specimen from the parent nodule: it exposes the fresh flint of the interior, bordered by its weathered crust. The flint itself is black with greyish mottling, and presents no sign of weathering since the formation of the crust, not even that thin bluish film which marks the first stage of patination. Irregular processes of the crust are however continued deep into the interior of the flint.

Both upper and under surfaces of the fragment are scored with scratches, some running parallel in groups which cross each other at various angles: most of the scratches are straight, but some are curvilinear. On the flat side they are confined for the most part to the weathered crust and its outlying patches, which were originally softer than the black flint. Some of the markings on this surface, which look remarkably like scratches, may possibly be of another nature, perhaps sponge spicules or other structures.

The origin of these scratches is doubtful ; glaciation, perhaps by coast ice, naturally suggests itself; but, as Professor Boule has pointed out, similar scratches are known to be produced by the intestine movements of rocks, and I have myself described a striking case of this kind from the Trias of Portskewit, near Bristol.

So far we have encountered nothing which may not be explained by natural causes. A fragment detached by a natural fracture from an already weathered chalk flint and subsequently scored all over with well-marked scratches; nothing more. We now encounter an interesting problem of a different kind. 
Two adjacent sides (Plate XIX., A, and Fig. 64), forming what we will call the front of the rhomb, rise steeply from the base and meet to form the anterior obtuse angle. They have been produced by a very remarkable flaking, and present a singularly artificial appearance. The flaking, though on' a larger scale, recalls indeed some examples of Aurignacian or Neolithic workmanship. (When first shown this specimen my spontaneous remark was "Aurignacian"! Singularly enough a distinguished French archæologist made the same exclamation when I showed the specimen to him.)
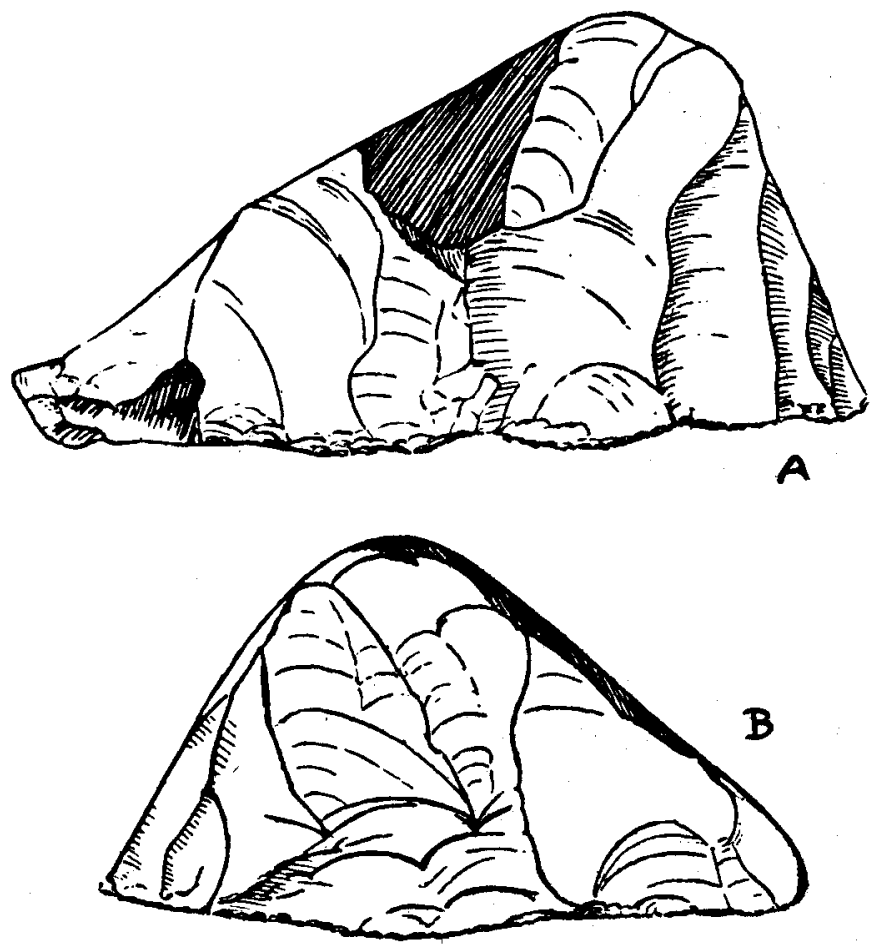

Fig. 64. The flaked faces of the Implement. A, Right hand ; $B$, Left hand face.

$\left(\frac{1}{l}\right)$

The flakes, mostly long and narrow, have been detached by a force acting from below upwards, in some cases almost vertically, in others more obliquely. On one side-the right, Fig. 64, A-they have been cleanly taken off and run, for the most part, from base to summit without interruption; on the other side-the left-the "workmanship" is not so neat; several flakings on the lower part of the face fail to reach the summit and lie deeper in the flint than those above them, the continuity of the surface has been lost, it is broken and hackly. 
This difference is connected with another. On the rightand it is a singular fact--the flaking traverses the deeply weathered crust only, and never extends deep enough inwards to reach the unaltered flint. It thus lies wholly in homogeneous material, hence its regularity. On the left it goes deeper and enters the flint core, in this place yellowish brown not black in colour; and it is precisely here, where a harder material is encountered, that the flaking becomes imperfect and confused; over the rest of this face, formed for the greater part of the weathered crust, the flaking resumes its regularity.

The edge where the flaked faces meet the base is marked by irregular minute secondary chipping, such as might be produced by use or otherwise.

If this specimen is indeed a manufactured implement, then the two anterior flaked sides or one of them must have been its functional edge or surface d'utilisation and, if so, then according to M. Rutot's excellent rule, we should find corresponding to this on the opposite sides the surface d'accomodation, as indeed we do! On the right posterior side the curve of a hinged fracture provides a rounded margin which originally met the upper surface at an acute angle, thus forming a fairly sharp edge which could not be grasped with comfort. It has accordingly been flaked away, the flaking, as is usual in such cases, being less regular, more "careless," than on the supposed working face.

On the left posterior side the rounded upper surface meets the flat base in an edge, and this has been battered down as if by repeated blows.

Thus the accommodation of the flint to the hand leaves nothing to be desired. So far we have indicated nothing which appears to be inconsistent with the view which would attribute the flaking of this specimen to intelligent design. We may next enquire whether it could have served any useful purpose. This question I think may also be answered in the affirmative.

On the right anterior face the flaking has produced a scalloped margin, rounded or angular bays alternating with sharp cusps. The edge of these bays is still capable, as may be shown by experiment, of scraping the sides of a stick, and might be used for smoothing the surface or shaping the point of a wooden spear.

The left anterior face ends below in a straight edge for $25 \mathrm{~mm}$. of its length, and would make an excellent scraper.

If this specimen has claims to be regarded as an implement, and more definitely as a scraper, we may next enquire whether we have any independent evidence to suggest the existence during Pliocene times of beings intelligent enough to fabricate such a tool.

Man, as we know him, is evidently excluded; Homo sapiens is a late Quaternary species, and is already replaced in the earlier Quaternary by divergent forms, such as the man of Neanderthal, of Heidelberg and of Piltdown; all differing from each other and 
from existing man more than existing men differ among themselves.

It is extremely doubtful whether the genus Homo had as yet come into existence in Pliocene times. So much is at least suggested by the Piltdown skull which we encounter before reaching the Pliocene, and which has been referred to a distinct genus with the name, not very appropriate, as Prof. Boule points out, of Eoanthropus.

This, however, is not a matter of vital importance, for the genus Homo must, on the hypothiesis of evolution, have been preceded by others, which in a continuous series linked it on to the apes, and some of these intermediate forms may have been quite capable of chipping a flint into a useful implement. Even the lower Catarrhine monkeys, as Romanes has pointed out, show a surprising appreciation of mechanical appliances devised by man, and the Anthropoid apes exceed them in the intelligent application of natural objects to mechanical ends; as an instance we may recall the performances of "Sally" the chimpanzee at the "Zoo"!

But between man and the existing higher apes there is a great intellectual gap, signalized by the difference in volume of the brain, the highest apes having a cranial capacity of only $600 \mathrm{cc}$. and the most primitive men of $1000 \mathrm{cc}$., and there may be-indeed are-differences in structure still more profound.

Given a race of Primates with an average cranial capacity of say $900 \mathrm{cc}$, what, we may ask, might be predicted of their intellectual powers?

Could we deny them the possession of speech, the art of kindling a fire, of sharpening a stick, or shaping a flint ?

We cannot give a definite answer to this question, but I think we may fairly admit that if such a race were in existence at the time the basal beds of the Red Crag were being deposited, it might have been capable of shaping the specimen under discussion.

Thus we meet the difficulty which has been educed from the Palæontological record.

But this is not the question before us. No one would deny that this and many other so-called "eoliths" could have been fabricated by man or his predecessors. What we have really to decide is whether we are in possession of sufficient evidence to prove that our specimen could not have been produced by natural forces but must have been shaped by intelligent design, and this is no easy task.

When passing through Paris last year I submitted my specimen to several of my French colleagues. Prof. Boule unhesitatingly rejected it from the category of artefacts and classed it with such naturally flaked flints as may be found in the lowest deposits of Aurillac. Prof. Capitan was willing to accept it, as he was at that time inclined to accept some of the Aurillac flints. M. Capitan had the kindness to show me his famous collection of these flints. Some of them are evidently of natural origin, 
others are suggestive of intelligent design. We were both agreed upon this point. But to me the two classes seemed to pass in to each other by the nicest gradations, and I found it impossible to discover any criterion by which they could be distinguished. M. Salomon Reinach was greatly impressed by the seemingly artificial character of the specimen, and borrowed it to make a plaster cast for the Museum at St. Germain : he considered it to be the best example of the kind he had seen, but for a final verdict he thought we must depend upon its associates. This also has been my opinion: noscitur a sociis.*

This leads us to the general question of the Sub-Crag " implements," which has already been fully discussed by Prof. Boule $\dagger$, and more briefly by met, so that it is scarcely necessary here to recapitulate the arguments which have been adduced against their artefact origin. I will only refer to a collection of the se flints which Mr. Reid Moir has presented comparatively recently to the British Museum and some selected specimens which he has had the kindness to send for my inspection from the Ipswich Museum and his own cabinet. All this material is full of interest; each specimen presents a problem in itself and demands special study, which I do not now propose to undertake.

The important point for our enquiry is that none of them, at least to my eyes, present the same kind of flaking as that which distinguishes our specimen. The character of the flaking is indeed almost as various as the specimens themselves.

On informing Mr. Reid Moir that I was unable to discover a fellow to our specimen he generously presented me with a verticallyflaked flint from his own collection, and informed me that another is in the possession of Sir E. Ray Lankester. From this it would appear that the type is far from common.

If I must criticise Mr. Moir's latest gift, I need not say more than this, that while presenting points of special interest it is not quite so suggestive of intelligent design as the one under consideration, and thus does not afford the confirmation which we seek. (I have seen since two specimens resembling it in Prof. Capitan's collection of Aurillac flints.)

Let us then turn once more to the original specimen itself. One singular feature which seems difficult to reconcile with its supposed use as an implement is the restriction of the flaking on the right anterior side to the weathered crust. The flakes taken from this side were flakes of the crust and not of the fint itself, which on this surface is not exposed. But the crust of a flint

* Since this was written I have again visited Prof. Capitan's collection of Aurillac flints, and was more than ever impressed by the artefact appearance of some of them, as Prof. Capitan remarked, "Nature and Man seem sometimes to make the same thing." "The resemblance of these Miocene flints to those from the base of the Red Crag is very striking, so much so that it is difficult ro resist the conclusion that the "eolith" question is not multiple, but one.

+" L'Anthropologie," Vol. 26, pp. 1 to 67, 1915.

¥" Ancient Hunters," 2nd Ed., p. 60. 
nodule is seldom hard enough to afford an edge sufficiently resistent for use. At present it is true the flaked surface is harder than steel and the edge consequently in good working order. This, however, is due to the presence of silica, which was deposited in the superficial pores of the crust subsequent to the flaking. When the skin thus formed is removed the : underlying crust is found to be still so soft that it may be readily scratched with a knife.

I do not see how to meet this difficulty except by supposing that the original crust was hard throughout and was subsequently softened by the removal of silica in solution. This is by no means improbable. The white crust of some flint nodules occurring in situ in the Chalk is so hard that it cannot be scratched by a knife.

Finally, the question may be put - if this flint is not an artefact, by what natural forces has it been fashioned? It is doubtful whether this question is as yet ripe for discussion, and I plead guilty to a certain temerity in offering the following remarks.

Chance blows can scarcely be invoked, for it is obvious that such blows, if they were the effective agents, must have been directed from below upwards, and have been delivered on the margin of the flat face or base. But it is extremely unlikely that chance blows would always hit the mark. Some ineffectual blows would almost certainly fall upon or near the margin, and if they did would inevitably be recorded by cones of percussion. Of such cones, even after careful examination with a lens, I can find no trace. It was precisely on such evidence as this that I assured myself of the artefact nature of the "Mesvinian" flints before they were definitely shown to be of Mousterian age.

It is of course conceivable that if the flint were embedded in a stiff clay with only its edges protruding that flakes might be removed by blows coming from one direction, as in a torrential stream or the waves of the sea coast, without random bruising of the flat face. But this hypothesis would involve a re-setting of the fragment, so that the anterior sides which meet in an angle should each be chipped, while the protection to the flat face remained unimpaired.

The action of pressure is not so readily disposed of. Its remarkable effects are now well known, and some of the chance forms it has produced are remarkably similar, as shewn by the Abbé Breuil, to special types of recognised flint implements.

That the flint has been subject to considerable and shifting pressure is shewn by the scratches both on its upper and lower faces. One group of these scratches running parallel to the edge of a flaked facet is at least extremely suggestive.

It is possible that both this and some other Sub-Crag flints will eventually prove to have been designed for use as implements, but at present the question seems to call for suspended judgement. It is eminently a case for the Scotch verdict of " not proven."

POSTSCRIPT BY THE AUTHOR. - This paper was read before the Geological Society of London, an 23rd January, 1918, but was 
not accepted for publication. I am greatly indebted, however, to the Council of the Society for their gracious permission to make use of my MS., and still more to the Prehistoric Society of East Anglia for giving me a place in their Proceedings. Much has happened in the interval; Prof. Marr and Mr. Miles Burkitt have accepted several of the flaked flints from the Red Crag as human artefacts, and, so I am informed, has that most distinguished authority, the Abbé Breuil. It is said that the Abbé is still of opinion that the so-called rostro-carinate forms have not been shaped by man, and I do not know what judgment he would pass on the specimen before us. The pseudo-Aurignacian flaking which characterises it is very different from the flat, squamous flaking of the specimens which he regards as genuine implements.

But the existence of a tool-making animal in Pliocene times (Eoanthropus has been suggested) now being conceded, the whole question assumes another aspect, and I am, for my part, convinced that the balance of probabilities is heavily in favour of the view that the flaking of our "Flaked Flint" was accomplished by human agency. Its remarkable Aurignacian facies presents us with a new problem, and opens up questions of great interest.

May I venture in conclusion to offer my congratulations to Mr. Reid Moir on his well-deserved triumph. No one yields to myself in admiration of the pertinacity, industry, and insight which have led him to establish the existence of a member of the human family during the later moiety of the Pliocene epoch.

\section{SOME FLAT-BASED CELTS FROM KENT AND DORSET.}

By Henry Dewey, F.G.S., of H.M. Geological Survey.

Read in London, March 27th, ro2o.

The following paper describes a number of celts that were found lying on the surface in several parts of North Kent and in Dorset.

They seldom occurred alone, but among numerous implements of other forms, in situations that suggest occupation sites of early peoples. During parts of several successive years the author examined the surface features of the Chalk Downs, and the contiguous belt of country to the north, formed by the Tertiary Beds, that lies between the valley of the Mole and that of the Medway. This work formed part of the official survey of the area, but during the examination the occurrence of any flint-implements was carefully recorded and the precise location given. It soon became obvious that the distribution of the implements was by no means general over the surface, but definitely restricted to certain sites 
Plate XIX.

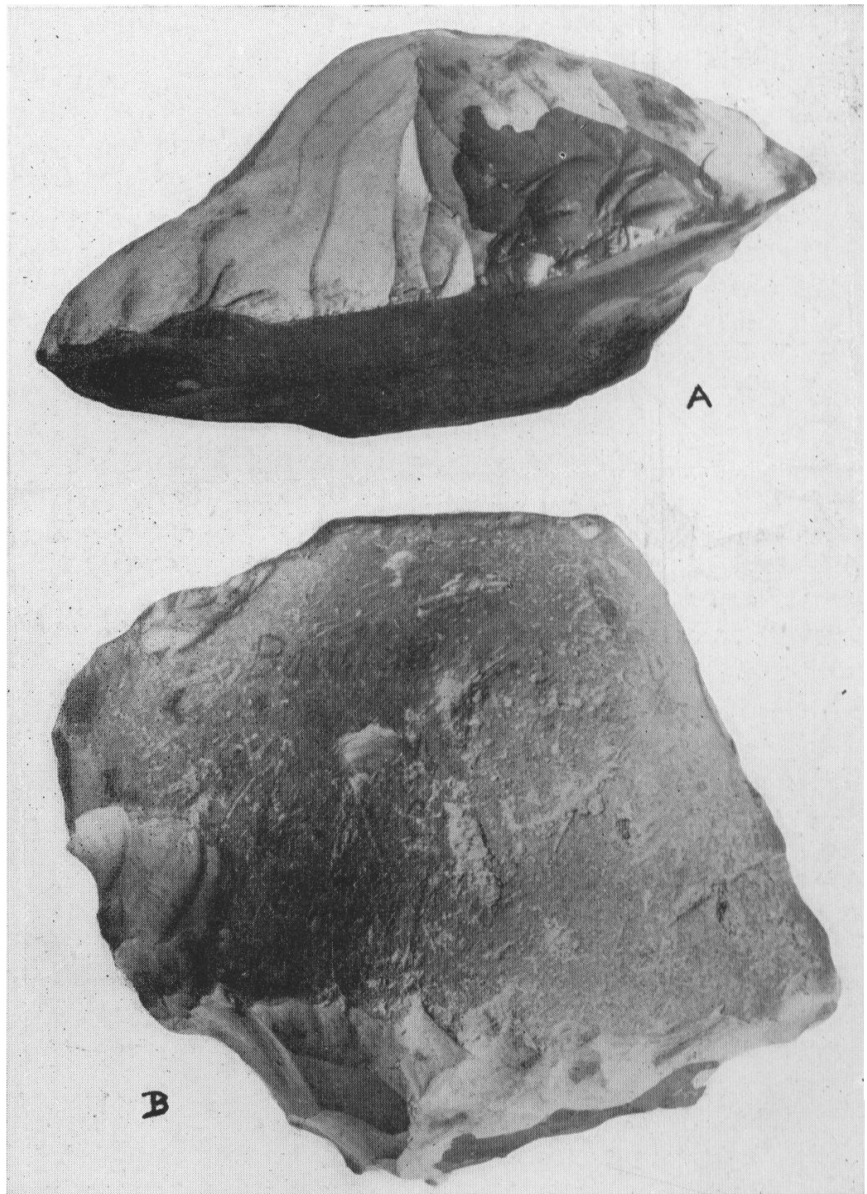

An Implement from the Red Crag, Bolton \& Laughlin's brickfield, Ipswich. A.- Seen from in front; B. -from above. 